\title{
E-government Frameworks based on Semantic Web Services: A Comprehensive Study
}

\author{
Naser N. Alazemi \\ Information Systems Dept. \\ Faculty of Computer and \\ Information Sciences \\ Helwan University, Egypt
}

\author{
Abdullah J. Al-Shehab \\ Basic Education College \\ Public Authority of Applied \\ Education and Training, \\ Kuwait
}

\author{
Hawaf Abd Alhakem \\ Information Systems Dept. \\ Faculty of Computer and \\ Information Sciences \\ Helwan University, Egypt
}

\begin{abstract}
E-Government is the civil and political conduct of the government which involves using information and communication technologies (ICT). Currently, it is facing several problems relating to integration of information and systems, extraction, and representation across heterogeneous organizations. Additionally, e-Government also encounters big challenges in achieving interoperability and integration; when differences in laws, regulations, services, administrative processes have to be accounted for, along with the different languages spoken across different regions and countries. There are numerous approaches, proposals, frameworks, and projects available to achieve semantic interoperability in the eGovernment domain; especially dealing with the creation and management of semantic web services. There is a lack of supporting methodology, specialized tools, and guidelines (which describe how formal semantic descriptions of the services in practical applications can be created and maintained). Moreover, in the e-Government paradigm, it is expected that formatted information be available in different ways, when presented to senior citizens or government officials, etc. Therefore, the e-government services need to provide information where format and methods of delivery adapt according to the users and situations. The semantic Web presents the information in a machine readable format and (strives to make e-government processes fully automated. In recent years, Semantic Web technologies based on ontology) have brought about promising solutions to the above engineering problems. This research presents a survey for some framework approaches for E-government by Semantic Web. It also discusses the platform namely Protégé ontology API for semantic ontology development in e-governments. The research would also be of interest to novice semantic Web researchers that might use it as a starting point for more investigations.
\end{abstract}

\section{Keywords}

E-government; Semantic Web; Domain ontology; Services; Linked data; owl

\section{INTRODUCTION}

The growing interest in semantic technologies within the egovernment paradigm is proved by the huge number of contemporary projects focusing on the exploitation of semantic knowledge for e-government. The e-government evolution is brought about by expansion and adoption based on communities, citizen, businesses and public administrations. In most countries, it's generally seen as a four-step process: presence phase, interaction phase, transaction phase and transformation phase. The Semantic Web provides an ontology-based framework for integration, searching and sharing of data drawn from various sources [1]. In this regard, the World Wide Web Consortium (W3C $)^{1}$ defines the Semantic Web as "the representation of data on the World Wide Web." Nowadays, W3C is examining several approaches, including OWL-S ${ }^{2}, \mathrm{WSMO}^{3}, \mathrm{SWSF}^{4}$, WSDL-S ${ }^{5}$ and SAWSDL $^{6}$, that will eventually lead to the achievement of a standard for Semantic Wen Services (SWS) technology. On the other hand, Tim Berners-Lee 2006 introduced the semantic Web architecture that contains eight layers [9] as shown in Figure 1. The Resource Description Framework (RDF) and Ontology are considered the most important layers of this structure. RDF is a language for creating a data model for objects (or 'resources') and to form relations among them. It enables us to represent information in the form of a graph. The Resource Description Framework Schema (RDFS) provides basic vocabulary for describing properties and classes of the RDF resources.

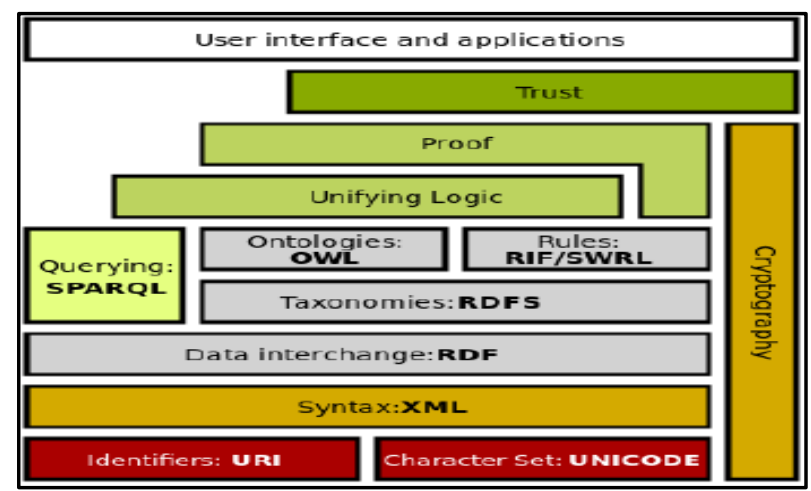

Fig.1: The semantic Web architecture

The goal of Access e-Government is to facilitate citizen access to the Public Administration (PA) services. This is to be established by making service browsing, discovery, and execution easier and more effective. Also, there are many egovernment applications that run by using various web services available online. Where one web service is not enough to fulfill the user requirements, the integration of e-government web services is needed. The Semantics platform provides the capability to model and represent the knowledge within a given domain by means of explicit formalization of key domain concepts; their attributes and relations; as well as their

\footnotetext{
${ }^{1}$ (www.w3.org/2001/sw)

${ }^{2}$ http://www.w3.org/Submission/OWL-S

${ }^{3}$ http://www.w3.org/Submission/WSMO/

${ }^{4}$ http://www.w3.org/Submission/SWSF/

${ }^{5}$ http://www.w3.org/Submission/WSDL-S

${ }^{6}$ http://www.w3.org/TR/sawsdl
} 
workflow sequences and structures. Figure 2 shows the scenario where e-government is applied in semantic web services.

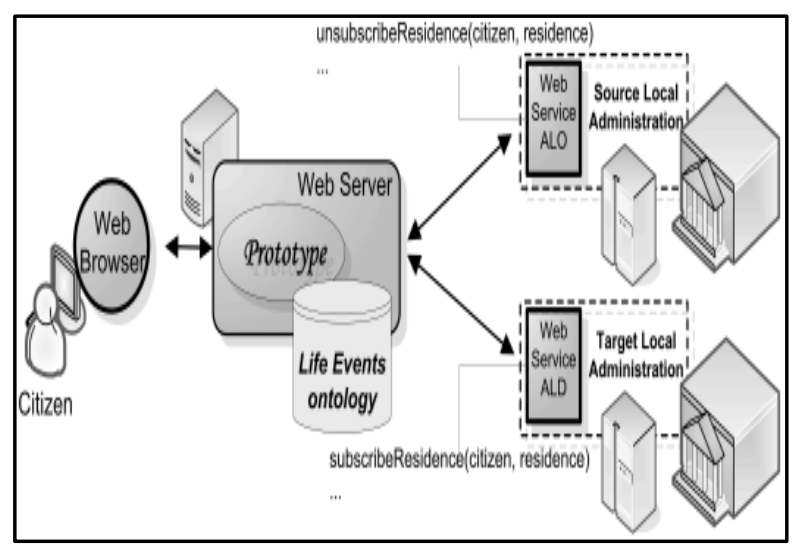

Fig 2: E-government Scenario (Adapted from [ [1]])

In semantic web, information is represented in a machine readable format, to make the e- government processes fully automated. It can be achieved with help of ontological descriptions of web services. Considering the heterogeneous and distributed nature of the e-Government domain, semantics can be effectively used as a common background platform for describing the processes and services provided by governmental institutions on various levels. The common platform then allows us to integrate the services and make them interoperable as well as transparent for end users (citizens andor businesses).

The paper is organized as follows: The section two reviews the challenges, abilities and problems faced by the e-government semantic techniques are applied in the e-government system. The section three shows the semantic description of Web services. Section four discusses semantic Web models and Frameworks that can be used for e-government. Section five displays the data and explains the integration of services. The conclusion is explained in section six.

\section{THE E-GOVERNMENT CHALLENGES AND ABILITIES}

E-Government, as mentioned above, is facing several problems in systems and information integration, information extraction, and information representation across heterogeneous organizations. As the benefits of e-Government technologies are becoming more apparent to the public, citizens are demanding more solutions in this area. However, no real indications to generate actual solutions have been provided. Also, the extensive use of semantic technology in the eGovernment paradigm has not really been covered as yet because of official advantages [10].

There are a lot of challenges when we implement semantic egovernment applications; this paper shows some challenges in general:

1. Semantic level: Data heterogeneity: How e-government services exchange information and meaningful messages. A semantic model has been developed to define business goals and modeling business processes in a semantic manner.

2. Technique Level: The middleware technology chosen to run an e-Government application must satisfy some requirements. We have to be careful with how egovernment services get integrated with various governmental systems, while guaranteeing semantic accuracies. Moreover, the interchange of information between involved entities must occur under certain conditions; heavy data/information security mechanisms are required.

3. How government intranets capture and use the knowledge about the government itself (services, resources, etc.). The dynamism of e-Government environments is another concern when developing applications in this domain. The new information and services can be made available at any time, whereas existing ones may disappear.

4. How government services can dynamically be configured based on the specification of citizen/ business needs.

On the other hand, significant challenges remain in egovernment, for which Semantic Web technologies might offer solutions. Semantic Web research directions that are relevant to e-government include:

a) Social networking;

b) Service composition and collaborative workflow;

c) Security and trust;

d) Automated collection and processing information; and

e) Adaptive information delivery.

\subsection{Problems while Applying Semantic Technologies in E-Government}

Based on the challenges defined above and on the research [2], some of the domain-specific weaknesses that make the application of semantic technologies in national and crossborder services difficult are:

- Public administration (PA) is politically driven, which means that decisions are not always taken rationally but are stained by political bias. For example, the semantic standardization process should pass through several types of central "controls" (of which technical excellence is just one).

- $\quad$ PA is still not sufficiently modeled, partly due to its size and complexity, and partly because there are no widely accepted representations/ models/definitions describing the domain. For instance, even the heavily used terms in the field like e-Governance, e-Government, e-Democracy, e-Participation, and e-Services are ill-defined.

- While size and complexity make the domain a challenging field to apply semantic technologies; at the same time, they cause confusion, especially to technical people that don't possess in-depth domain knowledge. The application of semantic technologies has not been coupled with a clear business view and development plan so far. Due to this situation, the e-Government initiatives are still usually technology driven, and thus lack a broader business perspective.

- A conservative organizational culture is prominent in public administration. As a result, we may witness intense reluctance or even resistance of PA actors for technologies that can potentially introduce dramatic changes in the current modus operandi. PA is usually a late adopter and not a pioneering environment where innovations can easily flourish.

- Finally, and with regard to the notion of the Pan-European e-Government Services (PEGS), it is important to mention 
that the policies related to public administration are institutionally out of the EU mandate. Although the notion and the need to move towards a European Administrative Space has been discussed in theory for some years now (e.g., in European Public Administration Network), there is still no EU mandate for developing standard policies for the European public administrations.

\section{E-GOVERNMENT WEB SERVICES}

The web Service architecture designed to overcome the "information isolated island" problem of e-government information, to facilitate the government information resource sharing system model as a distributed architecture which seamlessly integrates existing heterogeneous systems. It organizes a shared platform based on Web Service [30].

The issue of e-government information sharing can be resolved by using Web Service effectively and conveniently. The Web Service application in e-government will enhance the current deployment and decrease the cost of information integration. Web Service designing and development on distributed systems are playing important roles by making them adapt according to the modern web with massive everyday online tasks. [30].

Web service aims to achieve interoperability between web servers by using existing technologies; this is done by building blocks to enable integration of web services which are named as composition constructs. Composition constructs have two essential types in service composition [38]:

1. Control flow constructs (for process-oriented compositions): Its specification involves representing communication with atomic services to specify the execution of communications [32]. Communication primitives typically define a single interaction between a process and an atomic Web service.

This interaction has been applied by [32], and there is a wide agreement regarding the category each control flow pattern should be assigned to:

a. Basic control flow patterns are: sequence, parallel split, synchronization, exclusive choice, and simple merge.

b. Advanced control flow patterns include: multi-choice, loops, and similar.

2. Dataflow constructs (for data-oriented compositions): It's mean how information passed among Web benefits as much as the activities performed on the yield of an administration that is exchanged as contribution to another administration [36].

Each creation dialect (either by graphically wiring yields to inputs, e.g., in Yahoo! Funnels or by means of printed expressions e.g., in BPEL), bolsters the determination of the dataflow. Dataflow generally perform activities, for example, duplicating information (mapping), arranging information in specific criteria view (sorting), and consolidating information (blending).

There are two basic data passing paradigms defined by [37]: blackboard and explicit dataflow:

a. The blackboard paradigm stores data centrally in shared variables that are used as sources and targets by Web service activities. Several service composition languages follow this paradigm; among them is the BPEL.

b. The explicit dataflow paradigm makes dataflow an integral part of the composition model by means of dataflow connectors. A dataflow connector describes how data is manipulated and routed to or from the Web services.

Data transformations are other types of constructs; in order to ensure the data exchange between heterogeneous Web Services, Data Transformation instructions specified in the dataflow may include data manipulations. This is done with the aim to avoid mismatching output and input data formats; proper data transformation constructs are needed. Typically, transformations yield valid data from one schema and transfer them to valid data under another schema [39].

\section{SEMANTIC DESCRIPTION OF WEB SERVICES}

The core idea of the Semantic Web is to make information (available on the web) understandable not only by humans but also by machines. Semantic Web builds an additional layer on top of the existing World Wide Web. In said layer, the information has well-defined semantics, enabling the Web to become the universal medium for data, information and knowledge exchange7.

\section{A. Ontology:}

Ontologies and languages that can be used to describe them form the core of the Semantic Web. Ontology, as defined (in Gruber 1993) is a formal, explicit specification of a shared conceptualization of some domain knowledge. It is a valid description of domain knowledge; the domain members agree to follow the ontology for describing domain concepts.

Ontology is expressed in a language that is, depending on the language expressivity, capable of expressing declarative (i.e., concepts, attributes, relations) and procedural knowledge (also called axioms, implicit knowledge or rules). Ontologies can also be used to represent the viewpoint of citizens in the application; thus, making it easier for them to navigate through the different services and administrations. Ontologies enable the use of vocabulary about a certain domain in a coherent and consistent manner [20]. In short, ontologies are the tools for formalizing knowledge and encoding higher-level data models: such as life events, procedures and services.

In this aspect, there are two main types to build an ontology: the first is the 'specific domain ontology', which represents the specific meaning of terms as interpreted in the specific domain. The second is 'upper or Top-Level ontology', which represents the public concepts that are the same across all knowledge domains [3]. There are two types of building ontology: Manual developing and automatic developing. This process aims to build the domain ontology in semi-automatic or automatic process. The process starts by extracting the terms and concepts, etc. from the documents; the ontology learning is a subtask of information extraction. Figure 3 shows the pip-line for ontology based web services and Figure 4 shows the semantic services for OWL.

\footnotetext{
${ }^{7}$ http://www.w3.org/2001/sw/Activity.html
} 


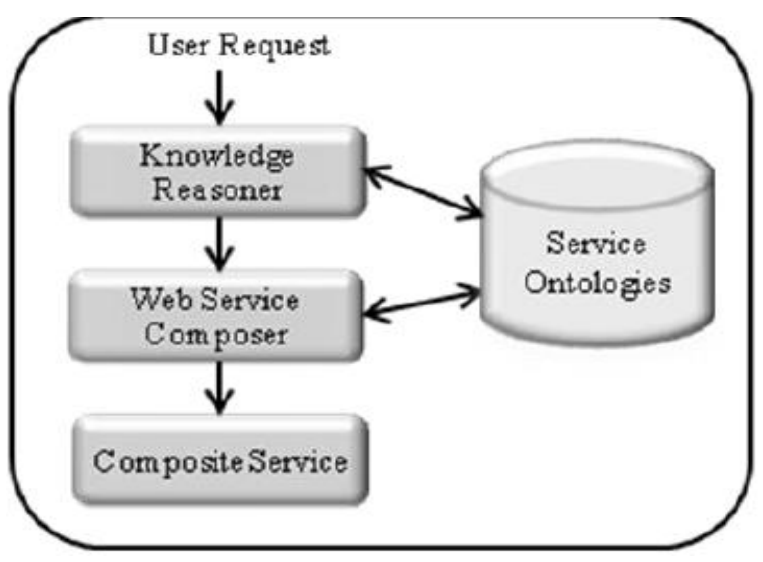

Fig 3: Ontology based web service composition (Adapted from [4]

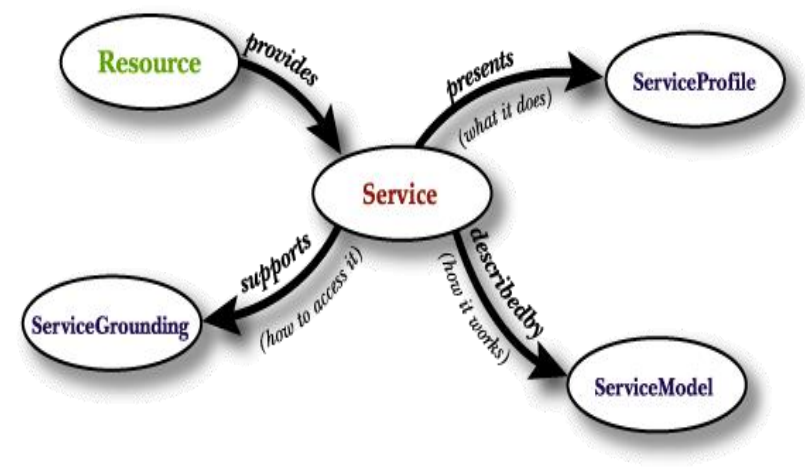

Fig 4: semantic services for OWL-S

\section{SEMANTIC WEB MODELS AND FRAMEWORKS FOR E- GOVERNMENT}

The e-government domain is an obvious and promising application field for ontologies. Since legislative knowledge is, by nature, formal to a large extent and its definition is shared by many stakeholders as shown in figure 5 , it makes the use of ontologies a viable choice. In fact, there are various contemporary e-government projects where semantic technologies are being used.

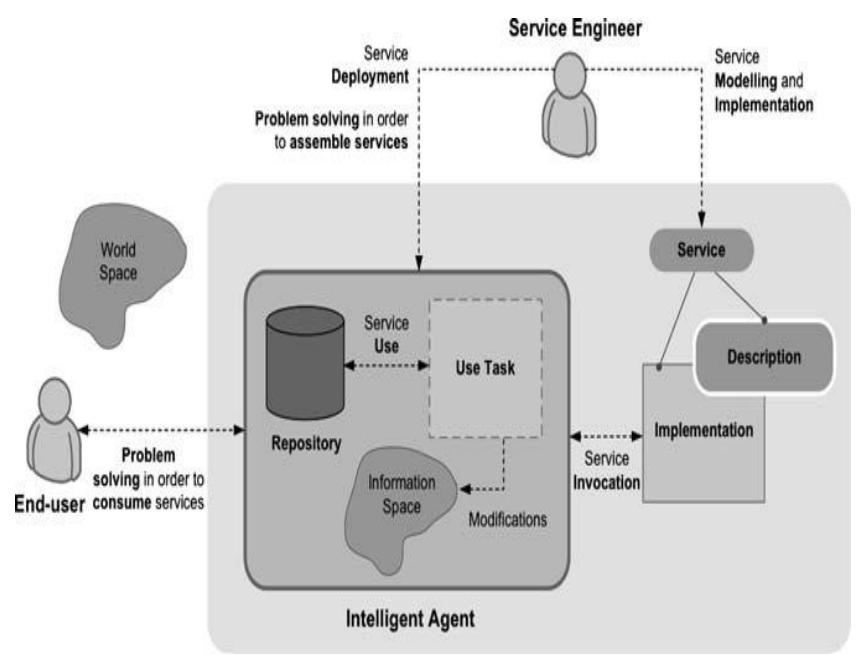

Fig. 5: Semantic Web Services environment (adapted from [2])
Many e-government projects are being developed and various approaches have been proposed for the design and the development of the architecture which will help deliver egovernment services to citizens. The eGOV project [12] proposes the architecture which enables 'one-stop government'. In order to describe the services, a markup language (GovML) has been developed [13]. GovML defines a set of metadata to describe public administration services and life events.

The EU-PUBLI.com project [14] defines a Unitary European Network Architecture. It proposes a middleware solution to connect heterogeneous systems of different public administrations and to enable a service-based cooperation between public administrations. The FASME project [15 focuses on supporting citizen mobility across European countries by the integration of administrative processes. In order to satisfy this objective, a smart card is provided to citizens for the storage of all personal information and documents. Services are delivered through dedicated kiosks.

The ONTOGOV project [16] is developing a platform that will facilitate the consistent composition, reconfiguration and evolution of e-government services. The e-POWER project [17] has employed knowledge modeling techniques for inferences like consistency check, harmonization and consistency enforcement in legislation. The SmartGov project [18] developed a knowledge based platform to assist public sector employees in generating on-line transaction services. figure 6 shows other projects for techniques and frameworks which are used in semantic web services for e-governments.

\begin{tabular}{|c|c|c|c|c|}
\hline \multirow{2}{*}{ Models } & \multicolumn{2}{|c|}{ Ontology } & \multirow{2}{*}{$\begin{array}{l}\text { Semantic } \\
\text { languageses }\end{array}$} & \multirow{2}{*}{ Country } \\
\hline & Data Concept & Serrice Concept & & \\
\hline$D C$ & . & . & RDF/XML & $\cdot$ \\
\hline vCard & Address, Contact & . & RDF/OWL & . \\
\hline GorML & PublicAuthority, law & $\begin{array}{l}\text { service-name, } \\
\text { procedure life event, } \\
\text { etc. }\end{array}$ & RDF & $\begin{array}{c}\text { Austria, Greece, } \\
\text { Switzerland }\end{array}$ \\
\hline oeGOV & $\begin{array}{l}\text { ExecutiveBranch, } \\
\text { Agency, Council, etc. }\end{array}$ & . & RDF/OWL, etc. & U.S. \\
\hline UK-GCIM & $\begin{array}{l}\text { Subjects/Identifiers } \\
\text { Rules Evidence, etc }\end{array}$ & $\begin{array}{l}\text { Service Interaction, } \\
\text { Outcomes, govemed by }\end{array}$ & $\mathrm{RDF}$ & $\mathrm{UK}$ \\
\hline GEA & $\begin{array}{c}\text { SocietalEntity, Evidence } \\
\text { ServiceProvider, } \\
\text { Placeholder, }\end{array}$ & $\begin{array}{c}\text { PA Service: } \\
\text { Precondition, Outcome }\end{array}$ & $\begin{array}{l}\text { OWL, RDF, } \\
\text { etc. }\end{array}$ & Europe \\
\hline FEA-RMO & $\begin{array}{l}\text { Data Reference Model: } \\
\text { GovernmentBody, etc. }\end{array}$ & $\begin{array}{l}\text { Services to Citizens, } \\
\text { etc. }\end{array}$ & OWL & U.S. \\
\hline MetaOntology & Legal/Organizationa & $\begin{array}{l}\text { OntoGovProfile, } \\
\text { OntoGovProcess }\end{array}$ & $\begin{array}{l}\text { KAON } \\
\text { OWL-S }\end{array}$ & $\begin{array}{l}\text { Switzerland, } \\
\text { Greece, and Spain }\end{array}$ \\
\hline
\end{tabular}

Fig. 6: services Modeling Approach (adapted from [5])

An ontological approach was presented by [40] to illustrate how e-services could be derived from citizens' needs expressed in the form of simple phrases for e-government service integration. This was done by using a semantic objective and a service discovery technique. The derived e-service ontologies were represented in OWL and the Web Service Modelling Language (WSML).

Muthaiyah and Kershberg in [7] proposed another ontological approach for semantic interoperability in e-government by using a shared hierarchal ontology. They organized knowledge at different levels by local ontologies. Mapping described a 
semantic bridging process methodology; the integration and merging of local ontologies was represented in OWL syntax.

In [41], e-government services were presented, in the form of a customer-oriented e-government Web portal hosted on an intelligent platform. This was achieved by presenting the notion of an intelligent document and a Life Event service, both of which are semantically modelled with the OWL ontology to enable services and related public administrations' interoperability. These allow automatic services composition, advanced searching mechanisms and better usability from the user's point of view.

A software engineering platform was proposed by [42] for the development and management of e-government services namely ONTOGOV. The ONTOGOV platform practices Semantic Web technologies using OWL-S and Web Service Modelling Ontology (WSMO) to build eight kinds of ontologies, describing the e-government domain; they include: organizational ontology, legal ontology, profile ontology, domain ontology, web service orchestration ontology, service ontology, life-event ontology and life-cycle ontology. The public administrators use these ontologies to describe and compose its services. The life-cycle ontology is used to achieve the maintenance of e-services (and the software components) and service ontology integration, done by web service orchestration ontology [43].

In [35], A multilevel abstraction of life-events for egovernment services integration was presented. They define a life-event as a collection of actions required to deliver a public service, satisfying the requirements of a citizen in a real-life scenario. It is modelled using three kinds of ontologies: egovernment ontology, regulatory ontology and service ontology. These ontologies are represented in OWL to allow the integration of dynamic services via semantic searching and matching of concepts [44].

Ontology-based approach for semantic interoperability in egovernment was presented by [43]. An E-government Business Ontology (EG-BOnt) was used to describe the business process of e-government services. Each business process is described in terms of its output, input, logical relations and resource constraints with other related businesses. Afterwards, each class of the EG-BOnt is defined using the OWL language for its strong semantic and logic relation expressiveness [45].

Finally, J. Vincent [6] presented a framework for generating semantic model ontologies in OWL syntax from a government service domain. He did this by first analyzing government services and then contracting domain ontology to get its semantic content to facilitate the design of e-government systems. This resulted in the provision of a usable framework for semantic knowledge representation in e-government processes.

Table 1 shows the survey of the techniques and frameworks which are used in semantic web services for e-governments.

\section{DATA AND SERVICES INTEGRATION}

The goal of data integration system is to provide uniform access to a set of heterogonous data sources and to free the user from the need to know about how data is structured at the sources and how it is to be reconciled in order to answer queries. Data integration is mostly achieved using one of the three approaches: Application Integration (mediation), database federation and data warehousing [11].

The generation of Ontologies is an important activity to enable semantic data integration. Efficiency in data integration can be achieved by Ontologies. The formation of ontology helps a range of applications that deliver the right information at the right time to make better informed decisions, throughout the lifecycle of discovery and development of various applications such as marketing. figure 7 displays the architecture of the semantic services. Thus, a range of semantic technologies, based on ontologies, enable the proper integration of knowledge in a way that is reusable by several applications across governance or business; from discovery to corporate affairs, more details as in [34].

(Ben Fadhel \& Kone, 2005) in [44] proposed the design and implementation of an e-government Web service platform as in the following figure 8 . This platform supports functionalities and modules of a Web service-based portal, which plays the role of an online middle man. The services request folder is an emulation of an electronic commerce shopping cart system. The service search module is a channel to make government services available. An online address change service is also presented at [45].

Table 1: Comparison For Frameworks And Technique Used Semantic In E-Government

\begin{tabular}{|c|c|c|c|}
\hline Ref. & Approach & $\begin{array}{l}\text { Domains } \\
\text { Used }\end{array}$ & $\begin{array}{l}\text { Applicatio } \\
\text { n }\end{array}$ \\
\hline $\begin{array}{l}\text { Jean } \\
\text { Vincent } \\
\text { et al, } \\
\mathbf{2 0 1 1} \\
\text { ACM }\end{array}$ & $\begin{array}{l}\text { Presents a case study, } \\
\text { combining an ontology } \\
\text { building methodology } \\
\text { and two state-of-the-art } \\
\text { Semantic Web } \\
\text { platforms; namely } \\
\text { Protégé and Java Jena } \\
\text { ontology API for } \\
\text { semantic ontology } \\
\text { development in e- } \\
\text { government. }\end{array}$ & $\begin{array}{l}\text { Uschold and } \\
\text { Kind }\end{array}$ & $\begin{array}{l}\text { developme } \\
\text { nt of } \\
\text { governmen } \\
\text { t domain } \\
\text { ontology }\end{array}$ \\
\hline $\begin{array}{l}\text { Lamhar } \\
\text { har et } \\
\text { al. } 2015 \\
\text { ACM }\end{array}$ & $\begin{array}{l}\text { Proposed an e- } \\
\text { Government KB for } \\
\text { Morocco. It is based on } \\
\text { a set of ontologies } \\
\text { (domain, legal, service, } \\
\text { SitCtx). }\end{array}$ & $\begin{array}{l}\text { Legal } \\
\text { ontology, } \\
\text { organization } \\
\text { al, domain, } \\
\text { service } \\
\text { ontology, } \\
\text { and } \\
\text { situation/co } \\
\text { ntext } \\
\text { ontology }\end{array}$ & $\begin{array}{l}\text { KB of } \\
\text { Moroccan } \\
\text { e- } \\
\text { Governmen } \\
\text { t that } \\
\text { represents a } \\
\text { big } \\
\text { challenge } \\
\text { in the } \\
\text { Moroccan } \\
\text { e- } \\
\text { Governmen } \\
\text { t. }\end{array}$ \\
\hline $\begin{array}{l}\text { Calo et } \\
\text { al. } 2014 \\
\text { ACM }\end{array}$ & $\begin{array}{l}\text {-Proposed a model for } \\
\text { the classification of } \\
\text { such concepts. The } \\
\text { model was built based } \\
\text { on literature review on } \\
\text { Gov-IS and Software } \\
\text { Engineering principles. } \\
\text {-introduces an extensive } \\
\text { list of benefits, barriers } \\
\text { and benefits, extracted } \\
\text { from the conducted }\end{array}$ & $\begin{array}{l}\text {-Implement } \\
\text { in four } \\
\text { countries- } \\
\text { Australia, } \\
\text { Estonia, } \\
\text { New } \\
\text { Zealand and } \\
\text { USA. }\end{array}$ & $\begin{array}{l}\text { Governmen } \\
\text { t sharing }\end{array}$ \\
\hline
\end{tabular}




\begin{tabular}{|c|c|c|c|}
\hline & $\begin{array}{l}\text { survey on the state of } \\
\text { the art on Gov-IS }\end{array}$ & & \\
\hline $\begin{array}{l}\text { Magro } \\
\text { et al. } \\
2013 \\
\text { ACM }\end{array}$ & $\begin{array}{l}\text { Proposed an approach } \\
\text { based on formal } \\
\text { ontologies and shows } \\
\text { how they can provide a } \\
\text { great enhancement in } \\
\text { this direction. }\end{array}$ & $\begin{array}{l}\text { booking } \\
\text { medical } \\
\text { examination } \\
\mathrm{s}, \\
\text { Payment } \\
\text { service for } \\
\text { medical fees }\end{array}$ & $\begin{array}{l}\text { Local } \\
\text { Italian } \\
\text { Public } \\
\text { Administra } \\
\text { tion }\end{array}$ \\
\hline $\begin{array}{l}\text { Patra et } \\
\text { al. } \\
2011 \\
\text { Acm }\end{array}$ & $\begin{array}{l}\text { Propose a framework } \\
\text { for monitoring the } \\
\text { compliance of Services- } \\
\text { based system (SBS) for } \\
\text { which a set of } \\
\text { requirements have been } \\
\text { pre-specified. }\end{array}$ & Use Case & $\begin{array}{l}\text { Monitoring } \\
\text { system }\end{array}$ \\
\hline $\begin{array}{l}\text { Kalamp } \\
\text { okis } \\
\text { et al. } \\
2013 \\
\text { ACM }\end{array}$ & $\begin{array}{l}\text { Discuss how Linked } \\
\text { Data has been used in } \\
\text { government data } \\
\text { provision so far and to } \\
\text { describe architecture } \\
\text { that will enable the } \\
\text { provision of integrated } \\
\text { government data around } \\
\text { real-world things in a } \\
\text { decentralized manner. }\end{array}$ & $\begin{array}{l}\text { Use Case: } \\
\text { Public } \\
\text { agencies } \\
\text { and schools } \\
\text { in Greece. }\end{array}$ & $\begin{array}{l}\text { Open } \\
\text { Governmen } \\
\text { t Data }\end{array}$ \\
\hline $\begin{array}{l}\text { Magout } \\
\text { as } \\
\text { et al. } \\
2010 \\
\text { Elsevie } \\
\mathbf{r}\end{array}$ & $\begin{array}{l}\text { Present and evaluate an } \\
\text { adaptive, semantic- } \\
\text { based framework for } \\
\text { monitoring citizen } \\
\text { satisfaction from e- } \\
\text { government services. }\end{array}$ & $\begin{array}{l}\text { Use case } \\
\text { Hypothesis, } \\
\text { opinion }\end{array}$ & $\begin{array}{l}\text { Monitoring } \\
\text { the degree } \\
\text { of citizen } \\
\text { satisfaction } \\
\text { from e- } \\
\text { governmen } \\
\text { t services. }\end{array}$ \\
\hline
\end{tabular}

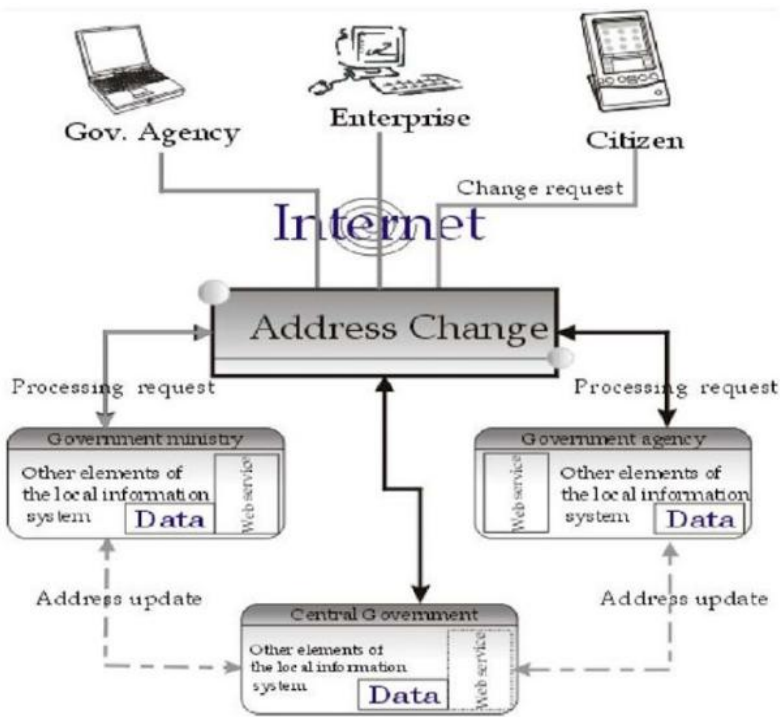

Fig. 8: Platform e-government Web service for address

\section{CONCLUSION}

The paper presents a survey on E-government framework and Web Services integration, using Semantic Web. The current research focusing on Semantic Web development, in the egovernment paradigm, does not refer to any existing ontology development methodology. The e-government specific ontology models that they have been developed or the ontology-based solutions for e-government services integration (and interoperability that they propose) have all been discussed. There is a lack of existing governmental services types, and the need to dramatically change (re-engineer) the way governmental services are presented to the end user, is also explained. The e-government services need to provide information where format and methods of delivery adapt according to the users and situations. One of the advantages of the semantic technique (in the enhancement of the government services) is the capability to formally describe meaning and context of the services; both traditional as well as electronic ones (provided as electronic forms or as web services), without the necessity to modify the services themselves. The plan in this paper to proposed a framework for constructing semantic model ontologies in OWL Web Service Standard for egovernment applications. The framework will be use simple ontology engineering techniques (modeling and representation techniques) to capture the semantic content of an e-government service, this makes the framework easy to understand and userfriendly, the platform employed includes protégé to create and import the OWL ontology.

\section{REFERENCES}

[1] F. Garc, R. Mart, J. M. Go, and R. Valencia-garc, Applying intelligent agents and semantic web services in eGovernment environments, J. Knowl. Eng., vol. 28, no. 5, 2011.

[2] V. Peristeras and K. Tarabanis, Semantic Technologies for EGovernment: An Overview, pp. 123, 2010.

[3] S. Zaidi, A Cross-language Information Retrieval Based on an Arabic Ontology in the Legal Domain, roceedings Int. Conf. Signal-Image Technol. Internet-Based Syst., pp. 8691, 2005.

[4] D. Mukhopadhyay and A. Chougule, A Framework for Semi-automated Web Service Composition in Semantic Web, 2013 (pp. 161-166). 
[5] H. Lamharhar and D. Chiadmi, Ontology-based knowledge representation for e-Government domain, 2015.

[6] Dombeu, Jean Vincent Fonou, and Magda Huisman. "Combining ontology development methodologies and semantic web platforms for e-government domain ontology development.” arXiv preprint arXiv:1104.4966 (2011)

[7] S. Muthaiyah and L. Kerschberg, Achieving Interoperability in Egovernment Services with two Modes of Semantic Bridging: SRS and SWRL, Journal of Theoretical and Applied Electronic Commerce Research, Vol. 3, No. 3, pp. 52-63, December, 2008.

[8] W. Zhang and Y. Wang, Towards Building a Semantic Grid for Egovernment Applications, WSEAS Transactions on Computer Research, Vol. 3, No. 4, April, 2008.

[9] T. Berners-Lee, Linked DataDesign Issues, W3C, 2006

[10] GUIJARRO, L. (2009) Semantic interoperability in eGovernment initiatives, Computer Standards and Interfaces, 31, 174180.

[11] Lacroix $Z$ and Crichlow $T$ (2003), Bioinformatics: Managing Scientific Data, Morgan Kaufman

[12] eGOV Project Website: http://www.egovproject.org

[13] Kavadias G., Tambouris E.: GovML: A Markup Language for Describing Public Services and Life Events. Working Conference on Knowledge Management in Electronic Government, 2003.

[14] The EU-PUBLI.con Project Website: http://www.eupubli.com

[15] The FASME Project Website: http://www.fasme.org/index-org.html

[16] OntoGov Project Website: http://www.ontogov.com

[17] Van Engers T., Patries J.M., Kordelaar J., Den Hartog J., Glasseee E. (2002). Available at http://lri.jur.uva.nl/epower/

[18] SmartGov Project Website: http://www.smartgovproject.org

[19] Gardner S. P. (2005) Ontologies and Semantic Data Integration, Drug Discovery Today, Vol. 10, Issue 14, p1001-1007

[20] http://what-when-how.com/information-scienceandtechnology/ semantic-web-in-e-governmentinformation-science/ (Accessed Date Aug 2016)

[21] F. Bettahar, C. Moulin and J.P. Barthes, Towards a Semantic Interoperability in an E-government Application, Electronic Journal of Egovernment, Vol. 7, No. 3, pp. 209-226, 2009

[22] Tirmizi, S. H., Sequeda, J., \& Miranker, D. (2008, January). Translating sql applications to the semantic web. In Database and Expert Systems Applications (pp. 450464). Springer Berlin Heidelberg.

[23] Ultrawrap. http://ribs.csres.utexas.edu/ultrawrap/

[24] D2R Server. http://www4.wiwiss.fu-berlin.de/bizer/d2rserver
[25] SquirrelRDF. http://jena.sourceforge.net/SquirrelRDF

[26] S. Das, S. Sundara and R. Cyganiak. R2RML: RDB to RDF Mapping Language. W3C Working Draft 24 March 2011, http://www.w3.org/TR/r2rml/

[27] Sahoo, S. S., Halb, W., Hellmann, S., Idehen, K., Thibodeau Jr, T., Auer, S. \& Ezzat, A. (2009). A survey of current approaches for mapping of relational databases to rdf. W3C RDB2RDF Incubator Group Report.

[28] http://www.semanticdesktop.org/ontologies/2007/11/01/pi mo/\#PersonalInformationModel

[29] J. Puustjarvi, Using Knowledge Management and Business Process in E-government, In Proceedings of the Information Integration and Web-based Applications and Services 2006 (iiWas2006) Conference, Yogyakarta Indonesia, pp. 381-390, 4-6 December, 2006.

[30] W. Ning, B. He, L. Hui, W. Xuehua, and W. Yanzhang, The Application of Web Service Technology in Government Information Resources Sharing System, 2009 IEEE/WIC/ACM Int. Jt. Conf. Web Intell. Intell. Agent Technol., vol. 3, pp. 373376, 2009

[31] A. L. Lemos, F. Daniel, and B. Benatallah, Web Service Composition: A Survey of Techniques and Tools, ACM Comput. Surv., vol. 48, no. 3, pp. 141, 2015.

[32] H. Tran, U. Zdun, and S. Dustdar, View-Based Integration of Process- Driven SOA Models at Various Abstraction Levels, in Model-Based Software and Data Integration, Berlin, Heidelberg: Springer Berlin Heidelberg, 2008, pp. 5566.

[33] W. M. P. van der Aalst, A. H. M. ter Hofstede, B Kiepuszewski, and A. P. Barros, Workflow Patterns, Distrib. Parallel Databases, vol. 14, no. 1, pp. 551, 2003.

[34] Drumm, Christian. "Integrating eGovernment Services using Semantic Web Technologies." In AAAI Spring Symposium: Semantic Web Meets eGovernment, pp. 1013. 2006.

[35] F. Sanati and J. Lu, Multilevel Life-event Abstraction Framework for E-government Service Integration, In Proceedings of the 9th European Conference on Egovernment 2009 (ECEG 2009), London, UK, pp. 550558, 29-30 June, 2009.

[36] Erhard Rahm and Philip A. Bernstein. 2001. A survey of approaches to automatic schema matching. VLDB Journal 10, 4 (2001), 334350

[37] Gustavo Alonso, Fabio Casati, Harumi Kuno, and VijayMachiraju. 2004a.Web Services: Concepts, Architec- tures and Application.Springer- Verlag.

[38] Dieter Fensel and Christoph Bussler. 2002. The web service modeling framework WSMF. Electronic Commerce Research and Applications 1, 2 (2002), 113137.

[39] Rodrigo Mantovaneli Pessoa, Eduardo Silva, Marten van Sinderen, Dick A. C. Quartel, and Lus Ferreira Pires. 2008. Enterprise interoperability with SOA: Survey of service composition approaches. In EDOC Workshops. 238251.

[40] P. Salhofer, B. Stadlhofer and G. Tretter, Ontology Driven E- government, Electronic Journal of E-government, Vol. 7, No. 4, pp. 415-424, 2009. 
[41] L.M.A. Sabucedo, L.E.A. Rifon, F. Corradini, A. Polzonetti and B. Re, Knowledge-based Platform for Egovernment Agents: A Web-based Solution Using Semantic Technologies, Journal of Expert Systems with Applications, Elsevier Inc., Vol. 2010, No. 37, pp. $3647-$ 3656, 2010.

[42] D. Apostolou, L. Stojanovic, T.P. Lobo, J.C. Miro and A. Papadakis Con- figuring E-government Services Using Ontologies, IFIP International Federation for Information Processing, Springer Boston, Vol. 2005, No. 189, pp. 1571-5736, 2005.

[43] Y. Xiao, M. Xioa and H. Zhao, An Ontology for Egovernment Knowledge Modelling and Interoperability, In Proceedings of IEEE International Conference on
Wireless Communications, Networking and Mobile Computing, (WiCOM 2007), Shanghai, pp. 3600-3603, 21-25 September, 2007.

[44] Fadhel, Ben Jafar, and Mamadou Tadiou Kone. "An eGovernment Web Services Platform on the Semantic Web." In EGOV (Workshops and Posters), pp. 143-149. 2005.

[45] J. Vincent, F. Dombeu, J. F. Dombeu, and M. Huisman, A Framework for Semantic Model Ontologies Generation for E-government Applications, ICDS 2011, Fifth, no. c, pp. 152158,2011 